\title{
$\mathrm{XX}$.
}

Aus der medizinischen Klinik zu StraBburg.

(Direktor: Geheimrat F. Moritz.)

\section{Über eine Methode der Bestimmung der Gesamtblutmenge beim Tier nebst Bemerkungen über die Veränderungen der letzteren bei Hunger und Mast.}

Von

Dr. Iouis Nelson*) aus Boston.

(Mit 1 Abbildung.)

Die klinisehe, wie die physiologisehe und experimentell-pathologische Forsehung der letzten Jahre hat die Notwendigkeit einer zuverlässigen und relativ unschwer ausführbaren Methode der Bestimmung der Gesamtblutmenge am Lebenden immer größer erscheinen lassen. Die Begriffe der Plethora und der Oligaemia vera entbehren immer einer sicheren Grundlage; ebenso harren zahlreiche Fragen der Kreislaufs- wie der Stoffwechselphysiologie mangels einer solchen Methode noch ihrer definitiven Entscheidung. Auf versehiedenen Wegen hat man diese Forderung zu erfullen gesucht; die wohl älteste unter den ernstlich in Betracht kommenden Methoden ist die bekannte von Welker(1) angegebene, von Haidenbain(2) und Gscheidlen(3) verbesserte, welche jedoch nur die Feststellung. von Standardzahlen ermöglicht hat; unter diesem Gesichtspunkte ist sie allerdings von bleibendem Wert. Eine Methode, die im oben angedeuteten Sinne verwendbar sein soll, muß an demselben Versuchsobjekte mehrmals ausgefthhrt werden können; alle späteren Methoden suchen denn auch dieser Forderung Rechnung zu tragen, so die Injektionsmethoden, die Methode der Bestimmung der Blutmenge durch teilweise Sättigung des Hämoglobins mit Kohlenoxyd sowie neuerdings die plethysmographische Methode von Mo ra w itz (4). Eine eingehende kritische Würdigung aller angefuhrten Verfahren findet sich in der

*) Der Verfasser hat die Arbeit vor etwa Jahresfrist abgeschlossen. Die Drucklegung verzögerte sich aus äußeren Gründen.

Moritz. 
Veröffentlichung des letztgenannten Autors, wir sehen deshalb von einer neuerlichen breiteren Erörterung ab.

Unter allen bisher angewandten Methoden haben sich - wenn wir von der noch nicht nachgeprüften plethysmographischen absehen - die Injektionsmethoden noch am meisten einzubürgern vermocht. In neuester Zeit hat speziell $\mathrm{Ho}$ f f m a n n (5) zahlreiche Untersuchungen derart angestellt, daß er isotonische Kochsalzlösungen intravenös injizierte und das Blutkörperchenvolumen vor und nach der Injektion mittels des Hämatokriten bestimmte. Dieser Methode steht allerdings das Bedenken entgegen, daß auch blutisotonische $\mathrm{NaCl}$-lösungen nach den Versuchen von Mag $\mathrm{nus}(6)$ sehr rasch die Blutbahn verlassen; größere ,Stabilität" mußte a priori jener Verdünnungsflüssigkeit zugesprochen werden, die zum Blute die größte Verwandtsohaft besitzt, d. i. dem Serum der gleichen Tierart. Ein diesbezüglicher Vorsehlag war bereits von Malassez (7) gemacht, aber bisher noch nicht syștematisch ausgeführt worden. Theoretisch ist anch dieses Prinzip nicht einwandfrei geblieben, da Decroly und Rousse (8), sowie Ransom (9) auch schwer diffusible Körper, (Antitoxine) rasch in die Lymphe übergehen sahen. Immerhin mußte es des Versuches wert erscheinen, eine auf der Verdünnung des Blutes durch artgleiches Serum beruhende Methode auszuarbeiten.

Auf Veranlassung von Hrn. Geheimrat Prof. Moritz habe ich im Laufe des zurückliegenden Jahres (1907)

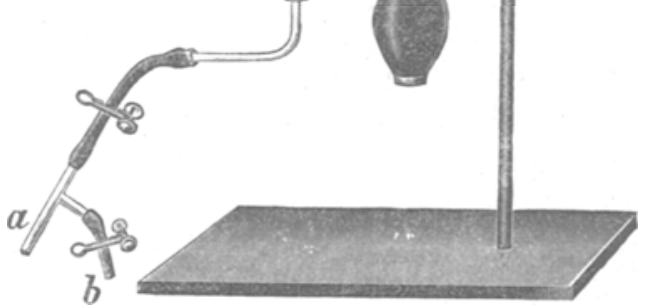

Fig. 1 eine Reihe von Versuchen angestellt, denen das letztangeführte Prinzip zugrunde lag; über die angewendete Methodik und die gewonnenen Resultate sei hier in Kürze berichtet.

\section{Methodik.}

Mittels des Thoma-Zeißschen Zählapparates wird bei einem Kaninchen die Zahl der roten Blutkörperchen im Ohrvenenblute festgestellt. Hierauf wird in eine Carotis (a in Fig. 1) des Tieres eine T-Kanüle eingebunden und eine bestimmte Menge Blat - meist 18 bis 
$40 \mathrm{ccm}$ abgelassen (aus b Fig. 1). Durch den anderen Schenkel der Kanüle - die zur Vermeidung von Verstopfung durch Gerinnsel mit Hirudinlösung benetzt ist - wird sofort nach der Blutentnahme eine genau gleiche Menge vorher bereitgestellten Serums injiziert. Die Injektion erfolgte mittels eines einfachen Apparats (s. Fig. 1), der im wesentlichen aus einer kalibrierten Burette, einem Doppelgebläse und einem Ausflußrohr besteht und es ermöglicht, in weit bequemerer Weise als mittels Trichter oder Spritze eine genau abgemessene Serummenge zu injizieren. Die Flïssigkeit in der Burette kann durch einen Warmwassermantel warm gehalten werden. Eine halbe Stande nach der Injektion wird eine neveriiche Bestimmung der Körperchenzahl im Ohrvenenblute vorgenommen. Das zur Verdünnung verwandte Serum wurde in folgender Weise gewonnen: Einem zweiten Kaninchen wurden ca. 70 bis $80 \mathrm{ccm}$ Blut aus der Carotis steril entnommen und in einem Meßzylinder aufgefangen. Beim Beginn der Gerinnung wird der obere Rand der Blutsäule vorsichtig mit einer ausgeglühten langen Nadel von der Wand des Gefäßes abgelöst, das letztere für 12 Stunden in den Eisschrank gestellt, hieranf das überstehende Serum abpipettiert und solange zentrifugiert bis es völlig klar ist (meist in 3 bis 4 Stunden). Diese Methodik hat sich uns mehr bewährt als etwa aus dem defibrinierten Blut durch Absitzenlassen oder Zentrifugieren das Serum zu gewinnen. Man bekommt es in dieser Weise kaum hämoglobinfrei und wir befürchteten deshalb Gerinnungen in dem Tier. Durch eine einfache Rechnung läßt sich sodann die Gesamtblutmenge ermitteln, nach der Formel:

$$
\mathrm{v}=\frac{\mathrm{a} \cdot \mathrm{c}}{\mathrm{a}-\mathrm{b}}
$$

wobei $\mathrm{v}$ das gesuchte Gesamtvolumen, a die ror, $b$ die nach dem Versuche festgestellte Blutkörperchenzahl und c die Menge des entnommenen Blutes bezw. des injizierten Serums bedeutet.

Die bei meinen Versuchen erhaltenen Resultate sind hier in tabellarischer Form zusammengestellt:

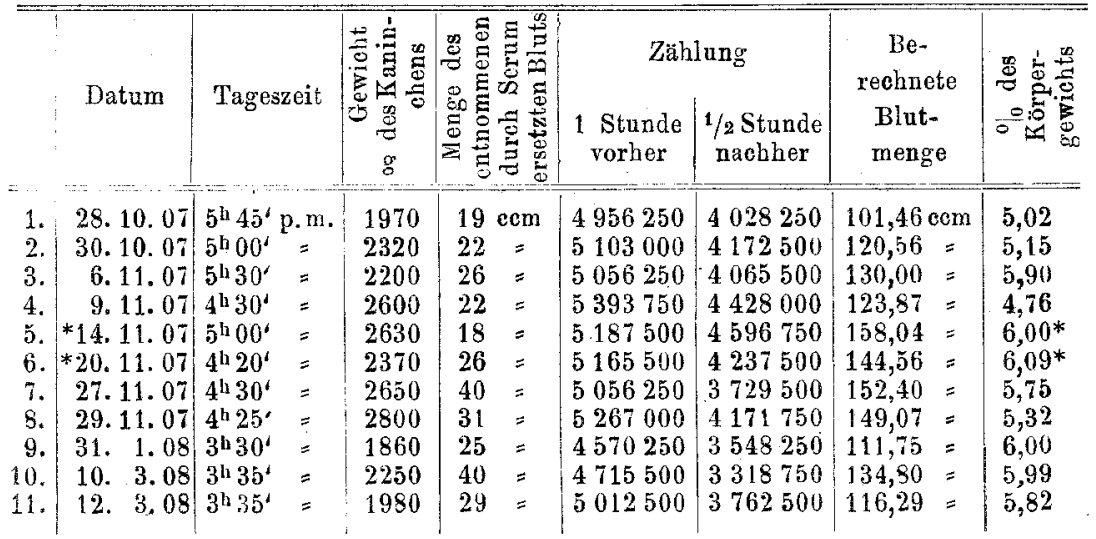


Naeh den mit der Welkerseben Methode angeführten Bestimmungen der Blutmenge bei Kauinchen sehwankt diese zwischen 4,5 bis 6,7 Proz. des Körpergewichts (zit. nach Herrmann, Handb. der Physiol.); die mit neuerer Methode gewonnenen Zahlen variieren in derselben Breite. Um direkte Vergleichwerte zu erzielen haben wir bei zwei Tieren (Versuch 10 und 11) unmittelbar an unseren Versuch die Welkersche Bestimmung angeschlossen. Im ersten Falle fanden wir nach Welker eine Gesamtblutmenge von 5,39 Proz. im zweiten eine solche von 6,06 Proz. des Körpergewichts, also verhältnismäßig unerhebliche Differenzen gegenüber unseren ersten Resultaten (5,99 Proz. resp. 5,82 Proz.). Bei einem Versuchstiere haben wir die Blutmenge zweinal nach unserer Methode bestimmt (Versuch 5 und 6 ); hier ergab sich eine außerordentlich gute Übereinstimmung (6,00 und 6,09 Proz.).

Die Brauchbarkeit der Methode erseheint uns damit erwiesen; auch ist ibre Technik keineswegs besonders schwierig. Wir sind nunmehr darangegangen, mit ihrer Hilfe die Frage nach dem Einflusse von Hunger und Mast auf die Gesamtblutmenge zu beantworten. Bekanntlich haben Moritz und sein Sehẗler Schieffer (10) eine deutliche Vergrößerung des Herzens bei Mast, eine Verkleinerung desselben nach längerem Hungern orthodiagrahpisch feststellen können und es mußte von Interesse sein, festzustellen inwieweit diese $\mathrm{Zn}$ - bezw. Abnahme des Herzvolums etwa auf Rechnung von mit der Veränderung des Körpergewichts gleichsinnigen Sebwankungen der Gesamtblutmenge zu setzen war.

Wenngleich unsere Versuche nach dieser Richtung noch wenig zahlreich sind, wollen wir hier doch in Kürze über sie berichten:

Hündin $\mathrm{I}$.

\begin{tabular}{c|c|c|c|c}
\hline \hline Zustand & $\begin{array}{c}\text { Gewioht } \\
\mathrm{g}\end{array}$ & $\begin{array}{c}\text { Rote Blut- } \\
\text { körperchen }\end{array}$ & $\begin{array}{c}\text { Blutmenge } \\
\text { com }\end{array}$ & $\begin{array}{c}\text { Prozent des } \\
\text { Körpergewichts }\end{array}$ \\
\hline \hline Normal & 5900 & 5167250 & 397,6 & 6,73 \\
Nach Hungern & 4700 & 6123250 & 372,0 & 7,91 \\
Nach längerem Hungern & 4060 & 5967000 & 324,8 & 8,00 \\
Nach Mästung & 6800 & 6931250 & 486,5 & 7,15
\end{tabular}

$\mathrm{H}$ ï $\mathrm{n}$ din II.

\begin{tabular}{c|c|c|c|c}
\hline \hline Zustand & $\begin{array}{c}\text { Gewicht } \\
\mathrm{g}\end{array}$ & $\begin{array}{c}\text { Rote Blut- } \\
\text { körperchen }\end{array}$ & $\begin{array}{c}\text { Blutmenge } \\
\text { cem }\end{array}$ & Prozent \\
\hline Normal & 8600 & 5945250 & 579,6 & 6,73 \\
Nach Hungern & 7000 & 6243000 & 565,11 & 8,07 \\
Nach Mästung & 9300 & 7602000 & 570,0 & 6,12 \\
Nach längerer Mästung & 10200 & 7307750 & 655,2 & $\mathbf{6 , 4 2}$
\end{tabular}


344 XX. L. Netson: Über eine Methode d. Bestimmung d. Gesamtblutmenge usw.

Aus diesen beiden 'Tabellen geht tabereinstimmend hervor, daß die Gesamtblutmenge in der Tat in naher Beziehung zum Ernährungszustande steht; die Änderung beider geht aber wenn auch gleiehmäßig, so doch nicht genau proportional zu einander. Die Blutmenge nimmt im Hunger in geringerem Maße ab als das Körpergewicht. In den Mastversuchen haben wir allerdings einmal eine tuber das $\mathrm{MaB}$ des Gewichtsansatzes hinausgehende Blutvermehrung feststellen können; im zweiten Versuche dagegen hielt die letztere mit der ersteren nicht völlig gleichen Sehritt. Doch erhöbte sich anch hier nach längerer Mast die prozentische Quote. Wie weit es sich hier um ein gesetzmäßiges Verhalten handelt, muß durch weitere Versuche entsehieden werden. Über Veränderungen der Blutmenge im Sinne der Veränderungen des Ernährungszustandes liegen auch von Schieffer schon einige Beobachtungen (nach der Welkerschen Methode) vor. Die Frage nach der Ursache der Veränderung der Herzgröße bei Hunger und Mast ist damit aber noch nicht endgültig beantwortet. Es müssen bierüber noch weitere Untersuchungen von versehiedenen Richtungen her gemacht werden.

\section{Literatur.}

1) Welker, Prager Vierteljahrsschr. 1854. Bd. IV und Ztschr. f. ration. Med. 1858, Bd. IV.

2) Heidenhain, Disquis. de sanguinis quantitate. Halle 1857 und Arch. f. physiol. Heilkunde $1857, \mathrm{Bd}$. I.

3) Gscheidlen, Unters. aus d. physiol. Laboratorium Wurzburg, Bd. II. Leipzig 1869.

4) Morawitz, Sammlung klin. Vorträge, N.F. No. 462.

5) Hoffmann, Arch. f. experim. Pathol. u. Pharm. Bd. 54 und Korr.-Bl. für Schweizer Ärzte 1907 No. 4 u. 5.

6) Magnus, Arch. f. experim. Pathol. u. Pharm. Bd. 44.

7) Malassez, Arch. de physiol. norm. et pathol. 1874, série 2, t. I et 1875, série 2, t. II.

8) Decroly et Rousse, Arch. internat. de pharmakolog. et de therapeut 1900 , t. VIII, 2, 3 .

9) Ransom, Ztschr. f. physiol. Chemie 1900, Bd. 29.

10) Schieffer, D. Arch. f klin. Med. H. 1 u. 2. 